Portland State University

PDXScholar

\title{
The Impact of Domestic Violence on Depression in Teen Mothers: Is the Fear or Threat of Violence Sufficient?
}

\author{
Barbara Mary Sussex \\ Portland State University \\ Kevin Corcoran \\ Portland State University
}

Follow this and additional works at: https://pdxscholar.library.pdx.edu/socwork_fac

Part of the Social Work Commons

Let us know how access to this document benefits you.

\section{Citation Details}

'The Impact of Domestic Violence on Depression in Teen Mothers: Is the Fear or Threat of Violence Sufficient?' Brief Treatment and Crisis Intervention, 5(1), 109-120. (w/ Barb Sussex).

This Article is brought to you for free and open access. It has been accepted for inclusion in School of Social Work Faculty Publications and Presentations by an authorized administrator of PDXScholar. Please contact us if we can make this document more accessible: pdxscholar@pdx.edu. 


\title{
The Impact of Domestic Violence on Depression in Teen Mothers: Is the Fear or Threat of Violence Sufficient?
}

\author{
Barb Sussex, PhD \\ Kevin Corcoran, PhD, JD
}

\begin{abstract}
The purpose of this study was to assess whether the fear or threat of intimate partner violence (IPV) impacted depression and peer support among a population of pregnant and parenting female adolescents, and whether cessation made a difference. The sample consisted of 286 teen mothers participating in a substance abuse prevention intervention. Data were self-report assessed at 6-month intervals from entry through 18 months. IPV was defined by a report of avoidance of another within the past 6 months out of fear or threat of violence and was also assessed for those aged 18 and older with measures from the Abuse Assessment Screen (AAS). Depression and peer support were measured using modified versions of the Center for Epidemiologic Studies-Depression scale and the Multidimensional Scale of Perceived Social Support, respectively. At baseline, $26.5 \%$ of participants reported avoiding someone out of fear or threat of violence in the past 6 months, and by the end of the study, 36.9\% reported avoidance at some time over 18 months. Mothers reporting IPV both subjectively (i.e., fear or threat) and directly (i.e., AAS) had significantly higher depression at the 12- and 18-month assessment periods, and those in continuous fear of IPV and new cases also had higher depression at 12 and 18 months. Cessation of IPV did not significantly affect depression scores. Regarding peer support, young women in IPV situations at baseline reported significantly less peer support at both baseline and the 6-month period. Additionally, findings suggest that peer support improves when the fear or threat of violence ends. Finally, correlations between peer support and depression show that as scores on peer support decreased, there was a concomitant increase in depression. [Brief Treatment and Crisis Intervention 5:109-120 (2005)]
\end{abstract}

KEY WORDS: domestic violence, depression, peer support, teen moms.

Over the past decade, abuse in dating relationships and intimate partner violence (IPV) ${ }^{1}$ against pregnant and parenting teenage women have emerged as significant health and social problems. While a considerable amount of information is known about IPV in general, very little research has been done on the incidence or impact of domestic violence among teen mothers. The prevalence and gender distribution of adolescent dating violence vary considerably. In a review of the literature, Hickman, Jaycox, and Aronoff (2004) found estimates of physical victimization among adolescent girls ranging from $8 \%$ to $57 \%$ and

\footnotetext{
${ }^{1}$ The terms intimate partner violence, domestic violence, abuse, and battering are used interchangeably in this paper.
} 
sexual victimization from $14 \%$ to $43 \%$. Females are significantly more likely than males to be sexually victimized (Halpern, Oslak, Young, Martin, \& Kupper, 2001) and to suffer more severe abuse and injury (Foshee, 1996; O'Keefe \& Treister, 1998).

Physical and sexual dating violence is intricately linked with adolescent pregnancy. No fewer than $25 \%$ and as many as $67 \%$ of teen mothers become pregnant through rape or incest, birth control sabotage, or other physical or sexual coercive behavior (Center for Assessment and Policy Development [CAPD], 2001). Gessner and Perham-Hester (1998) in a population-based study found that $66 \%$ of all births to teens under age 16 were from statutory rape. Abused high school girls are four to six times more likely to have been pregnant than their nonabused peers (Silverman, Raj, Mucci, \& Hathaway, 2001).

Many young women who leave an abusive dating relationship return when they discover they are pregnant, for fear of being alone and having to raise a child, only to find that the abuse may escalate during pregnancy. Investigators have reported rates of physical violence against pregnant adolescents before and during pregnancy ranging from $20 \%$ to $62 \%$ (Center for Impact Research, 2000; Martin, Clark, Lynch, Kupper, \& Cilenti, 1999; Parker, McFarlane, \& Soeken, 1994; Wiemann, Agurcia, Berenson, Volk, \& Rickert, 2000). Younger age appears to be a consistent risk factor for physical assault, with prevalence rates among pregnant adolescents one and a half to three times greater than those for pregnant adults (Curry, Perrin, \& Wall, 1998; Gessner \& Perham-Hester, 1998; Parker,

From Insights Teen Parent Program, Portland, Oregon (Sussex), and the Graduate School of Social Work, Portland State University, Portland, Oregon (Corcoran).

Contact author: Barb Sussex, Insights Teen Parent Program, 2020 SE Powell, Portland, OR 97202. E-mail: bsussex@ insightstpp.org.

doi:10.1093/brief-treatment/mhi005
McFarlane, Soeken, Torres, \& Campbell, 1993). Recent studies suggest that teen mothers may be at increased risk of physical assault during the postpartum period. In a prospective study that followed 570 adolescents for 24 months postpartum, Harrykissoon, Rickert, and Wiemann (2002) found that $41 \%$ of teen mothers experienced physical violence within the first 24 months of delivery, with the highest prevalence $(21 \%)$ during the first 3 months postpartum. An important finding was that $78 \%$ who reported abuse at 3 months postpartum had not experienced it before delivery, and there was a $3 \%$ to $7 \%$ increase in new cases at each 3-month follow-up.

Pregnant and parenting teens are particularly vulnerable to abusive partner relationships. These teens may romanticize love and believe that control and possessiveness are signs of it (Coley \& Chase-Lansdale, 1998; Walton, Weatherall, \& Jackson, 2002). This is particularly true for teens who witnessed domestic violence in their childhood homes, as they learn to tolerate abuse and confuse jealousy with love. Compared with adult women, teenage women have fewer options and resources for leaving an abusive relationship. Osofsky, Hann, and Peebles (1993) in a review of the literature found that teen mothers suffered from depression, low self-efficacy, and low self-esteem, which made them more susceptible to dependency on a controlling male. In addition, pregnant and parenting teens may be suffering abuse from more than one perpetrator, including parents, relatives, and/or peers. Findings from a study of 724 battered pregnant adolescents by Wiemann et al. (2000) suggest that these young women live in "violence-prone environments" (p. 93) and that abuse is not an isolated event, but rather a continuum that often begins in childhood and proceeds through dating relationships and into adulthood.

Research on the relationship between social isolation and/or peer support and IPV among 
adolescent mothers is scant. A review of the literature on peer relationships and teen mothers by Richardson, Barbour, and Bubenzer (1995) found no evidence that teen parenthood caused changes in peer support. In fact, compared with family, friends provided more emotional support and buffered the stress from parenting. Research on adult samples of battered women has found peer and family support to be protective factors against partner-perpetrated violence and to provide avenues for leaving an abusive relationship (Gielen, O'Campo, Faden, Kass, \& Xue, 1994; O'Campo, McDonnell, Gielen, Burke, \& Chen, 2002). Studies with samples of abused female adolescents report mixed findings. In qualitative exploration with abused female adolescents, many young women report their partners as being jealous of their friends and using controlling behavior to enforce social isolation (Jackson, 2001). However, Wiemann et al. (2000), in a study of 724 pregnant adolescents, found no differences in the amount of social support available to battered pregnant teens in comparison with those who had not been physically assaulted.

Violence is associated with a host of health risks and psychosocial problems for abused female adolescents, such as physical injuries, reproductive health consequences, sexual risk taking and promiscuity (Silverman et al., 2001; Valois, Oeltmann, Waller, \& Hussey, 1999), antisocial and violent behavior (Roberts, Klein, \& Fisher, 2003), multiple substance use (Martin et al., 1999), eating disorders (Ackard \& Neumark-Sztainer, 2002; Silverman et al., 2001), and depression and suicidality (Silverman et al., 2001; Roberts et al., 2003). However, most research on associations between abuse and health risks involve cross-sectional studies, thus the directionality of and relationship between associations remain unclear.

Longitudinal studies among adult women with a history of IPV have examined both the temporal relationship of abuse and depression and the effect of abuse cessation on depression. In a meta-analysis of the literature on the prevalence of mental health problems among women with a history of IPV, Golding (1999) reported clear evidence of a dose-response relationship of violence to depression and posttraumatic stress disorder. Katz and Arias (1999) found that psychological abuse using dominance/social isolation behaviors resulted in subsequent increases in depressive symptoms among college-aged women. In a 2-year longitudinal study on the effects of cessation of abuse, Kernic, Holt, Stoner, Wolf, and Rivara (2003) found that among women with a history of physical/sexual abuse and psychological abuse, cessation of both types resulted in a $35 \%$ decline in the likelihood of depression. The course of depressive symptoms among pregnant teens from their third trimester through 4 months postpartum was examined by Barnet, Joffe, Duggan, Wilson, and Repke (1996); conflict with the baby's father was strongly associated with increased rates of depressive symptoms. The most comprehensive study of the relationship between IPV and subsequent problem behavior was conducted by Roberts et al. (2003) using baseline and 11-month follow-up data for 4,595 adolescents from the Add Health study. Significant associations were found between IPV and longitudinal increases in depressed mood, illicit substance use, antisocial behavior, and suicidality among female adolescents. As well, depressed mood was associated with subsequent involvement in an abusive relationship.

This study examines the impact of domestic violence on depression and peer support. Data were collected over an 18-month period. There were two research questions: Does the fear or threat of domestic violence impact depression and peer support, and does cessation make a difference? 


\section{Methodology}

\section{Research Participants and Procedures}

The sample consisted of 286 pregnant and/or parenting teenage women who volunteered to participate in a randomized control trial comparing in-home substance abuse prevention counseling using motivational interviewing with standard services. Data consisted of self-reports by the teens and were collected through pen-and-paper surveys at baseline and at 6-, 12-, and 18-month follow-up points. The random assignment had no impact on the course of the study, and the groups were collapsed for the study of teen mothers and the fear or threat of domestic violence.

Participants were ethnically and racially diverse, with $41 \%$ white, $23 \%$ African American, 16\% Hispanic, and 20\% reporting mixed race/ethnicity. At the beginning of the study, teens ranged in age from 13 to 18 years, with a mean age of 17. Most participants $(67.1 \%)$ were parenting a child, and about $5 \%$ of these teens were pregnant as well. The remaining teens $(29.5 \%)$ were pregnant and not parenting. The majority of participants were pursuing a high school diploma or general equivalency degree. Forty-six percent had already earned their diploma and were either parenting full-time or looking for employment.

\section{Operationalization}

The independent variable of IPV was defined in three ways. The first was by reporting that one had avoided a partner or family member out of fear or threat of IPV within the past 6 months, which was considered for each assessment period. Because of limitations due to mandatory reporting for youths under 18 years of age, a more direct measure of domestic violence was not approved by the institutional review board.
This indirect measure is a suitable alternative, conveys the added quality of the young woman having to "run and hide," and allows for determination of whether the fear or threat of IPV is sufficient to adversely affect teen mothers.

This indirect measure not only precludes any concern about mandatory reporting, but is likely a valid assessment. It was associated with the self-report by those 18 years and older at the 18-month point in response to two questions from the Abuse Assessment Screen (AAS) (McFarlane, Parker, Soeken, \& Bullock, 1992) of having been "emotionally or physically abused by your partner, the father of your child(ren), a family member, or someone else important to you" in the past 6 months $\left(\chi^{2}=5.12, p<.05\right)$. Avoiding another out of fear or threat of IPV was also associated with reports of having been "hit, slapped, kicked or otherwise physically hurt by your partner, the father of your child(ren), or someone else important to you" in the past 6 months $\left(\chi^{2}=6.29, p<.01\right)$.

For the second definition of IPV, women were categorized into one of four groups: (1) those with no IPV at baseline and none at the 6-month assessment; (2) those with IPV at baseline and reporting none at 6 months (IPV-Stop); (3) those making a new report of IPV at 6 months while having reported none at baseline (IPV-New); and (4) those reporting IPV at baseline and continuing at 6 months (IPV-Continuous). The groups represented essentially short-term changes from baseline to the 6-month period. The categorization was repeated for longer-term changes by calculating groups from baseline to the 12-month period. This operationalization, then, consisted of two sets of the four groups: (1) baseline to 6 months and (2) baseline to 12 months; the groups in the latter set were independent of what was reported at the 6-month period.

IPV was also defined as endorsment of the AAS items about having been emotionally or physically abused and having been physically hurt in the past 6 months. Again, these operational 
definitions were restricted to those women 18 years and older and were ascertained only at the 18-month follow-up period in order to include the maximum number of research participants.

The dependent variables were depression and peer support. Depression was defined by scores on a seven-item version of the Center for Epidemiologic Studies-Depression scale (Radloff, 1977) using a 4-point (0 to 3) Likert scale. The instrument has very good reliability and validity (Corcoran \& Fischer, 2000), and the current sample has an internal consistency coefficient of .82. Peer support was defined by scores on a seven-item "peer support" scale adapted from the Multidimensional Scale of Perceived Social Support (Zimet, Dahlem, Zimet, \& Farley, 1988). Peer support is defined as the emotional attachment and availability of a friend, which may include a family member. The instrument had an internal consistency coefficient of .95 for the current sample. Scores were included in the analytic samples if the youth answered at least $75 \%$ of the items.

\section{Results}

\section{Incidents of Fear or Threat of Intimate Partner Violence}

At baseline, 74 teens $(26.5 \%)$ reported avoiding another out of fear or threat of violence in the past 6 months. This figure is alarming, as it indicates that about 1 out of 4 pregnant or parenting teens is likely to be in a violent relationship. This rate is deceptively stable in appearance over 6 months, 12 months, and 18 months at $25.1 \%$ (57/227), $20.7 \%$ (43/208), and $22.7 \%$ (45/198), respectively. These figures, however, fail to exclude cases in which the fear or threat stopped, and they include new cases at each assessment period. The percentages $(n)$ of new cases at the 6-, 12-, and 18-month points were $14.7 \%$ (33), $13.5 \%$ (28), and $14.0 \%$ (28), respectively. By the end of the study, $36.9 \%$ of the women reported avoidance at some time over the year and a half. This increase is influenced to some degree by the fact that women reporting avoidance out of fear or threat at baseline were less likely to attrite from the study. Therefore, any inference to prevalence would be misguided, as the number of IPV participants disproportionately increased over time.

\section{Impact of Intimate Partner Violence on Depression}

When the first definition of IPV was applied to each assessment period separately, there were significant differences for depression at the 12-month and 18-month assessment periods between teens reporting IPV and those not reporting IPV, with the former having higher depression scores. These results are displayed in Table I.

The effects of the fear or threat of IPV on depression over time are reported in Table II. The data were first analyzed with analysis of variance (ANOVA) for repeated measures. Because of the equal sample sizes for all time periods and the partitioning of variance for time by four IPV groups, the results showed no significant differences between the groups over time.

There were significant differences for depression scores at the 18-month follow-up between the groups when IPV was measured from baseline to 6 months. Higher scores were observed for those reporting IPV-Continuous and for new cases in which the threat or fear began at the 6-month period. When IPV was measured from baseline to 12 months, there were significant differences between groups for depression scores at the 12- and 18-month assessments. These results suggest that new incidents at 12 months had a fairly immediate impact on depression scores and continued to affect depression at the 18-month period. 
TABLE 1. The Impact of Fear or Threat of Intimate Partner Violence (IPV) on Depression and Peer Support at Each Assessment Period

\begin{tabular}{|c|c|c|c|c|c|c|c|}
\hline \multirow[b]{2}{*}{ Measures } & \multicolumn{3}{|c|}{$\begin{array}{l}\text { Teens Reporting Fear } \\
\text { or Threat of IPV }\end{array}$} & \multicolumn{3}{|c|}{$\begin{array}{l}\text { Teens Reporting No Fear } \\
\text { or Threat of IPV }\end{array}$} & \multirow[b]{2}{*}{$t$ Test } \\
\hline & $M$ & $S D$ & $n$ & $M$ & $S D$ & $n$ & \\
\hline \multicolumn{8}{|l|}{ Baseline } \\
\hline Depression & 2.09 & .64 & 74 & 2.04 & .62 & 205 & $<1.0$ \\
\hline Peer support & 3.17 & .94 & 73 & 3.53 & .68 & 204 & $3.48^{*}$ \\
\hline \multicolumn{8}{|l|}{6 months } \\
\hline Depression & 2.11 & .63 & 56 & 1.98 & .63 & 174 & $-1.35, n s$ \\
\hline Peer support & 3.29 & .81 & 56 & 3.46 & .78 & 176 & $1.37, n s$ \\
\hline \multicolumn{8}{|l|}{12 months } \\
\hline Depression & 2.19 & .69 & 48 & 1.89 & .61 & 176 & $-2.89^{*}$ \\
\hline Peer support & 3.49 & .73 & 48 & 3.47 & .78 & 175 & $<1.0$ \\
\hline \multicolumn{8}{|l|}{18 months } \\
\hline Depression & 2.17 & .65 & 51 & 1.88 & .53 & 160 & $3.21^{*}$ \\
\hline Peer support & 3.40 & .87 & 51 & 3.44 & .81 & 162 & $<1.0$ \\
\hline
\end{tabular}

${ }^{*} p<.01$.

As for cessation of IPV, the IPV-Stop group was not significantly different from women reporting no IPV, regardless of whether measured from baseline to 6 months or to 12 months. The mean scores were also quite stable over time. The results do not support the notion that cessation of the threat or fear of violence reduces the effects on depression. After all, those with cessation are not more depressed than teen mothers with no domestic violence.

The impact of IPV on depression was more directly assessed using the self-report of emotional or physical abuse at the 18-month period for women 18 years and older. The average depression score was $2.56(S D=.67)$ for women reporting emotional or physical abuse $(n=31)$ and $1.86(S D=.52)$ for those reporting no abuse $(n=137)$. These means were statistically significantly different, $t(166)=3.6$, $p<.00$. Similar findings were found when IPV was defined as having been hit, slapped, kicked, or otherwise physically hurt in the past 6 months. With this definition, women reporting IPV $(n=26)$ had an average depression score of $2.15(S D=.61)$, while women reporting no IPV $(n=142)$ had an average score of $1.89(S D=.56), t(166)=2.1, p<.05$.

\section{Impact of Intimate Partner Violence on Peer Support}

Data on the effects of the fear or threat of IPV on peer support at each separate assessment period also are displayed in Table I, and they evidence an impact only at baseline among teens experiencing IPV reporting lower peer support.

The means and standard deviations for peer support scores over time for the IPV groups are displayed in Table III. A repeated-measures ANOVA evidenced significant differences in peer support scores due to IPV at baseline and 6 months, $F(9,177)=2.5, p<.05$, and for IPV from baseline to 12 months, $F(9,178)=2.4$, $p<.01$, for Groups $\times$ Time interaction. Post-hoc analyses failed to discern significant differences using Bonferroni's multiple comparisons.

Significant differences for IPV groups measured from baseline to 6 months were observed for peer support scores at baseline and the 6-month period, and approached significance 
TABLE 2. Mean and Standard Deviation Scores for Depression, by Four IPV Groups

\begin{tabular}{|c|c|c|c|c|c|c|c|c|c|c|c|c|c|}
\hline \multirow{3}{*}{$\begin{array}{l}\text { Depression } \\
\text { at }\end{array}$} & \multicolumn{9}{|c|}{ IPV Groups: Baseline Through 6 Months } & & & & \multirow[b]{3}{*}{$F$} \\
\hline & \multicolumn{3}{|c|}{$\begin{array}{c}\text { No IPV at Baseline } \\
\text { \& } 6 \text { Months }\end{array}$} & \multicolumn{3}{|c|}{$\begin{array}{l}\text { IPV-Stop at } \\
6 \text { Months }\end{array}$} & \multicolumn{3}{|c|}{$\begin{array}{l}\text { IPV-New } \\
\text { at } 6 \text { Months }\end{array}$} & \multicolumn{3}{|c|}{ IPV-Continuous } & \\
\hline & $M$ & $S D$ & $N$ & $M$ & $S D$ & $n$ & $M$ & $S D$ & $N$ & $M$ & $S D$ & $n$ & \\
\hline Baseline & 2.03 & .59 & 137 & 1.93 & .64 & 33 & 2.19 & .75 & 26 & 2.25 & .64 & 31 & $\begin{array}{l}F(3,226) \\
=1.87 \\
p=.13\end{array}$ \\
\hline 6 months & 1.99 & .62 & 134 & 1.94 & .68 & 33 & 2.06 & .64 & 25 & 2.15 & .63 & 31 & $\begin{array}{l}F(3,222) \\
=<1.0, \\
n s\end{array}$ \\
\hline 12 months & 1.92 & .62 & 126 & 1.79 & .49 & 29 & 1.99 & .79 & 20 & 2.08 & .67 & 28 & $\begin{array}{l}F(3,202) \\
=1.01, \\
p=n s\end{array}$ \\
\hline 18 months & 1.90 & .45 & 114 & 1.74 & .59 & 28 & 2.17 & .76 & 19 & 2.19 & .74 & 28 & $\begin{array}{l}F(3,188) \\
=4.17 \\
p<.01\end{array}$ \\
\hline$F$ & & $\begin{array}{l}05)= \\
<.10\end{array}$ & & $F(3$, & 9) $<$ & & $F(3$, & 9 ) $<$ & & & 9) $<$ & & \\
\hline
\end{tabular}

IPV Groups: Baseline Through 12 Months

\begin{tabular}{|c|c|c|c|c|c|c|c|c|c|c|c|c|c|}
\hline \multirow{2}{*}{$\begin{array}{l}\text { Depression } \\
\text { at }\end{array}$} & \multicolumn{3}{|c|}{$\begin{array}{l}\text { No IPV at Baseline } \\
\quad \& 12 \text { Months }\end{array}$} & \multicolumn{3}{|c|}{$\begin{array}{l}\text { IPV-Stop at } \\
12 \text { Months }\end{array}$} & \multicolumn{3}{|c|}{$\begin{array}{l}\text { IPV-New at } \\
12 \text { Months }\end{array}$} & \multicolumn{3}{|c|}{ IPV-Continuous } & \multirow[b]{2}{*}{$F$} \\
\hline & $M$ & $S D$ & $N$ & $M$ & $S D$ & $n$ & $M$ & $S D$ & $n$ & $M$ & $S D$ & $n$ & \\
\hline Baseline & 2.03 & .61 & 133 & 1.98 & .61 & 37 & 2.19 & .61 & 26 & 2.22 & .66 & 22 & $\begin{array}{l}F(3,217) \\
=1.28 \\
p=\mathrm{ns}\end{array}$ \\
\hline 6 months & 1.99 & .62 & 124 & 1.91 & .67 & 34 & 1.99 & .63 & 20 & 2.18 & .64 & 22 & $\begin{array}{l}F(3,199) \\
=<1.0, n s\end{array}$ \\
\hline 12 months & 1.91 & .63 & 133 & 1.86 & .57 & 37 & 2.27 & .74 & 26 & 2.09 & .64 & 22 & $\begin{array}{l}F(3,217) \\
=2.98 \\
p<.05\end{array}$ \\
\hline 18 months & 1.90 & .46 & 114 & 1.80 & .66 & 35 & 2.23 & .57 & 24 & 2.16 & .84 & 20 & $\begin{array}{l}F(3,192) \\
=4.07 \\
p<.05\end{array}$ \\
\hline$F$ & $F(3,1)$ & $=2.1$ & $<.10$ & $F(3$, & 9) $<$ & & $F(3$, & 6) $<$ & & & $0)<$ & & \\
\hline
\end{tabular}

IPV = intimate partner violence.

at 18 months. The differences are such that women in IPV situations at baseline had less peer support at both baseline and the 6-month period. New cases of IPV do not show an impact over the course of about a year. Similar findings were noted for IPV groups derived from baseline to 12 months. The results approached significant difference on peer support scores at baseline and the 6-month period only. New cases also did not report an immediate impact of IPV on peer support. As for the cessation question, there was evidence suggesting that scores on peer support improve when the fear or threat of violence ends. This finding was 
TABLE 3. Mean and Standard Deviation Scores for Peer Support, by Four IPV Groups

IPV Groups: Baseline Through 6 Months

\begin{tabular}{|c|c|c|c|c|c|c|c|c|c|c|c|c|c|}
\hline \multirow{2}{*}{$\begin{array}{l}\text { Peer } \\
\text { support } \\
\text { at }\end{array}$} & \multicolumn{3}{|c|}{$\begin{array}{c}\text { No IPV at Baseline } \\
\text { \& } 6 \text { Months }\end{array}$} & \multicolumn{3}{|c|}{$\begin{array}{l}\text { IPV-Stop at } \\
6 \text { Months }\end{array}$} & \multicolumn{3}{|c|}{$\begin{array}{l}\text { IPV-New at } \\
6 \text { Months }\end{array}$} & \multicolumn{3}{|c|}{ IPV-Continuous } & \multirow[b]{2}{*}{$F$} \\
\hline & $M$ & $S D$ & $n$ & $M$ & $S D$ & $n$ & $M$ & $S D$ & $n$ & $M$ & $S D$ & $n$ & \\
\hline Baseline & 3.50 & .67 & 137 & 3.17 & .97 & 32 & 3.45 & .85 & 26 & 3.13 & .88 & 31 & $\begin{array}{l}F(3,225) \\
=2.99 \\
p<.05\end{array}$ \\
\hline 6 months & 3.51 & .75 & 137 & 3.26 & .89 & 33 & 3.53 & .65 & 25 & 3.11 & .88 & 31 & $\begin{array}{l}F(3,222) \\
=2.96 \\
p<.05\end{array}$ \\
\hline 12 months & 3.44 & .82 & 126 & 3.59 & .62 & 29 & 3.48 & .75 & 20 & 3.39 & .76 & 27 & $\begin{array}{l}F(3,201) \\
<1.0, \text { ns }\end{array}$ \\
\hline 18 months & 3.41 & .82 & 115 & 3.71 & .51 & 28 & 3.43 & .82 & 19 & 3.24 & .96 & 28 & $\begin{array}{l}F(3,189) \\
=2.16 \\
p<.09\end{array}$ \\
\hline$F$ & $F(3$, & 09) & & $F(3,24)$ & 3.48 & $<.05$ & $F(3,17)$ & 2.06, & $=.15$ & $F(3,2$ & $=1$ & , ns & \\
\hline
\end{tabular}

IPV Groups: Baseline Through 12 Months

\begin{tabular}{|c|c|c|c|c|c|c|c|c|c|c|c|c|c|}
\hline \multirow{2}{*}{$\begin{array}{l}\text { Peer } \\
\text { support } \\
\text { at }\end{array}$} & \multicolumn{3}{|c|}{$\begin{array}{l}\text { No IPV at Baseline } \\
\text { \& } 12 \text { Months }\end{array}$} & \multicolumn{3}{|c|}{$\begin{array}{l}\text { IPV-Stop at } \\
12 \text { Months }\end{array}$} & \multicolumn{3}{|c|}{$\begin{array}{l}\text { IPV-New at } \\
12 \text { Months }\end{array}$} & \multicolumn{3}{|c|}{ IPV-Continuous } & \multirow[b]{2}{*}{$F$} \\
\hline & $M$ & $S D$ & $n$ & $M$ & $S D$ & $n$ & $M$ & $S D$ & $n$ & $M$ & $S D$ & $n$ & \\
\hline Baseline & 3.49 & .71 & 133 & 3.15 & .97 & 37 & 3.54 & .77 & 26 & 3.32 & .81 & 22 & $\begin{array}{l}F(3,217)= \\
2.25,=.08\end{array}$ \\
\hline 6 months & 3.48 & .77 & 125 & 3.17 & .84 & 35 & 3.61 & .68 & 22 & 3.22 & .99 & 22 & $\begin{array}{l}F(3,203)= \\
2.26, \\
p=.08\end{array}$ \\
\hline 12 months & 3.43 & .82 & 133 & 3.56 & .66 & 36 & 3.58 & .69 & 26 & 3.38 & .79 & 22 & $\begin{array}{l}F(3,216)< \\
1.0, \text { ns }\end{array}$ \\
\hline 18 months & 3.45 & .77 & 115 & 3.48 & .91 & 35 & 3.35 & .86 & 24 & 3.31 & .86 & 20 & $\begin{array}{l}F(3,193)< \\
1.0, \text { ns }\end{array}$ \\
\hline$F$ & \multicolumn{3}{|c|}{$F(3,107)<1.0$} & \multicolumn{3}{|c|}{$F(3,29)=4.19, p<.01$} & \multicolumn{3}{|c|}{$F(3,17)=1.05, n s$} & \multicolumn{3}{|c|}{$F(3,17)<1.0, n s$} & \\
\hline
\end{tabular}

IPV = intimate partner violence.

observed when the fear or threat of IPV ended at 6 or 12 months.

At the 18-month follow-up period on peer support, women 18 and older who reported abuse were different from those reporting no abuse. Those reporting abuse $(n=31)$ had an average peer support scale score of 3.1 ( $S D=$ .88), while those women reporting no abuse $(n=138)$ had an average score of $3.5(S D=.75)$. This difference was not due to chance, $t(167)=$ $-2.5, p<.01$. There was a trend toward significant difference between those women reporting having been hit, slapped, kicked, or otherwise physically hurt ( $n=26, M=3.19$, $S D=.84)$ and those reporting no such abuse, $n=143, M=3.49, S D=.77 ; t(167)=-1.79$, $p=.07$.

\section{Depression and Peer Support}

Since one manifestation of domestic tyranny is enforced social isolation, it was important to 
TABLE 4. Correlation Coefficient Between Depression and Peer Support for Women Without Intimate Partner Violence (IPV), any IPV, and Continuous IPV

\begin{tabular}{|c|c|c|c|c|}
\hline \multirow[b]{2}{*}{ IPV Condition } & \multicolumn{4}{|c|}{ Assessment Time } \\
\hline & Baseline & $\begin{array}{c}6 \\
\text { Months }\end{array}$ & $\begin{array}{c}12 \\
\text { Months }\end{array}$ & $\begin{array}{c}18 \\
\text { Months }\end{array}$ \\
\hline $\begin{array}{l}\text { Without } \\
\text { IPV }(n=137)\end{array}$ & $-.24^{\star \star}$ & $-.17^{\star}$ & $-.44^{\star \star}$ & $-.27^{\star \star}$ \\
\hline $\begin{array}{l}\text { With any } \\
\text { IPV }(n=147)\end{array}$ & $-.25^{\star \star}$ & $-.24^{*}$ & $-.49^{\star \star}$ & $-.41^{\star \star}$ \\
\hline $\begin{array}{l}\text { With IPV } \\
\text { baseline to } 6 \\
\text { months }(n=30)\end{array}$ & $-.07, n s$ & $-.20, n s$ & $-.55^{\star \star}$ & $-.66^{\star *}$ \\
\hline
\end{tabular}

${ }^{*} p<.05,{ }^{* *} p<.01$.

consider the association between peer support and depression. These correlation coefficients are displayed in Table IV, clearly demonstrating that as scores on peer support decreased, there was a concomitant increase in depression. Since some theories assert that depression is the result of an absence of social interactions (e.g., MacPhillamy \& Lewinsohn, 1982), these findings are as would be expected. However, noteworthy are the different magnitudes of the associations for women reporting no IPV and those reporting some form of it, either over the course of the study or from baseline to 6 months. There was about $7 \%$ common variance between depression and peer support at the 18month period for women reporting no IPV, which contrasts with the $17 \%$ and $43.5 \%$ shared variance for women with any IPV and those with IPV continuing from baseline to 6 months. These findings suggest that IPV is likely to increase depression while concomitantly decreasing peer support, with the magnitude of this association between the two dependent variables increasing as IPV continues over time.

The results do not allow a determination of whether IPV leads to less peer support, which leads to depression, or causes depression, which in turns leads to less support. Regardless of the causal sequence, these findings clearly illustrate that IPV has an adverse impact on depression and peer support. While the association is variable for women without IPV, the negative associations seem to strengthen for women in any IPV setting and for those for whom the threat or fear of violence continues over time.

\section{Implications and Limitations}

The results of this study suggest that avoiding another out of fear or threat of domestic violence is fairly common for pregnant and parenting adolescents, and that even the fear or threat of IPV has an impact on depression for new incidents and for those in which the fear or threat continues over 6 or 12 months. Also, emotional abuse and actual physical harm have a significant impact on depression for young mothers 18 and older. The impact of cessation of violence was not discernible, as women who report that the fear or threat stopped were not distinguishable from women reporting no domestic violence.

Similar findings were observed for the impact of the fear or threat of IPV on peer support. With peer support, in contrast to depression, the results suggest that cessation of the threat or fear has an impact on scores, with more support observed almost immediately after reporting that the fear or threat has stopped. The findings here are in contrast to those of Wiemann et al. (2000) but consistent with reports of teens from Jackson's (2001) qualitative study.

There were limitations to this study. Chief among them was the operational definition of domestic violence. Even though the purpose was to determine whether a fear or threat would adversely affect teen mothers, using domestic violence as a measure indirectly widened the scope of those included. That is, some women would be included as victims of IPV when in fact they would be excluded with a more narrow definition, such as that of an assault. 
Additionally, even for the group that indicated no fear or threat, an error could be allowed by including those who may be in violent situations but have no fear. Thus, the four groups of domestic violence are not necessarily discrete. The likely impact of this is that the magnitude of the differences will be averaged out. In other words, the likely impact of domestic violence on depression and peer support will be stronger and more persuasive with groups that are more rigorously defined, as suggested from the results for women 18 and older at the 18-month assessment period. However, this definition too has limitations; for example, some women may not endorse the item of having been hit, kicked, or otherwise physically hurt because they interpret the behaviors together; that is, while they may have been hit, they may not endorse the item because they were not physically hurt.

Despite these limitations, the results of this study add to our knowledge of abuse among teen mothers and suggest that even the fear or the threat of domestic violence is sufficient to have some adverse impact on depression, with somewhat less impact on social support. This is the first study to examine IPV among teen mothers and associations with depression and peer support over time. While the data reveal interesting associations, findings do not allow for determining the critical causal relationship between IPV and depression as it interacts with peer support, and further study is warranted. Social workers and others involved in working with pregnant and parenting teen women need to be attentive to the possibility of IPV when conducting needs assessments, to assess peer support and to screen for depression.

\section{Acknowledgment}

This study was funded by the Center for Substance Abuse Prevention, U.S. Department of
Health and Human Services, Grant No. 4 UDl SP08264-03-4. The views expressed herein are solely those of the authors.

\section{References}

Ackard, D., \& Neumark-Sztainer, D. (2002). Date violence and date rape among adolescents: Associations with disordered eating behaviors and psychological health. Child Abuse and Neglect, 26, 455-473.

Barnett, B., Joffe, A., Duggan, A., Wilson, M., \& Repke, J. (1996). Depressive symptoms, stress, and social support in pregnant and postpartum adolescents. Archives of Pediatric and Adolescent Medicine, 150, 64-69.

Center for Assessment and Policy Development. (2001). Interpersonal violence and adolescent pregnancy: Prevalence and implications for practice and policy. Bala Cynwyd, PA:

National Organization on Adolescent Pregnancy, Parenting, and Prevention, Inc. Retrieved November 24, 2004, from http:// www.noappp.org/downloads/ finalreportviolenceandadolescentpregnancy.pdf Center for Impact Research. (2000). Domestic violence and birth control sabotage: A report from the Teen Parent Project. Chicago: Author. Retrieved November 24, 2004, from http:// www.impactresearch.org/documents/ dvandbirthcontrol.pdf

Coley, R., \& Chase-Lansdale, P. (1998). Adolescent pregnancy and parenthood: Recent evidence and future directions. American Psychologist, 53, 152-166.

Corcoran, K., \& Fischer, J. (2000). Measures for clinical practice: A sourcebook (Vol. 2, Adults). New York: Free Press.

Curry, M., Perrin, N., \& Wall, E. (1998). Effects of abuse on maternal complications and birth weight in adult and adolescent women. Obstetrics and Gynecology, 92, 530-534.

Foshee, V. (1996). Gender differences in adolescent dating abuse prevalence, types and injuries. Health Education Research, 11, 275-286. 
Gessner, B., \& Perham-Hester, K. (1998).

Experience of violence among teenage mothers in Alaska. Journal of Adolescent Health, 22, 383-388.

Gielen, A., O'Campo, P., Faden, R., Kass, N., \& Xue, S. (1994). Interpersonal conflict and physical violence during the childbearing year. Social Science Medicine, 39, 781-787.

Golding, J. (1999). Intimate partner violence as a risk factor for mental disorders: A metaanalysis. Journal of Family Violence, 14, 99-132.

Halpern, C., Oslak, S., Young, M., Martin, S., \& Kupper, L. (2001). Partner violence among adolescents in opposite-sex romantic relationships: Findings from the National Longitudinal Study of Adolescent Health. American Journal of Public Health, 91, 1679-1685.

Harrykissoon, S., Rickert, V., \& Wiemann, C. (2002). Prevalence and patterns of intimate partner violence among adolescent mothers during the postpartum period. Archives of Pediatric and Adolescent Medicine, 156, 325-330.

Hickman, L., Jaycox, L., \& Aronoff, J. (2004). Dating violence among adolescents: Prevalence, gender distribution, and prevention program effectiveness. Violence and Abuse, 5, 123-142.

Jackson, S. (2001). Happily never after: Young women's stories of abuse in heterosexual love relationships. Feminism and Psychology, 11, 305-321.

Katz, J., \& Arias, I. (1999). Psychological abuse and depressive symptoms in dating women: Do different types of abuse have differential effects? Journal of Family Violence, 14, 281-295.

Kernic, M., Holt, V., Stoner, J., Wolf, M., \& Rivara, F. (2003). Resolution of depression among victims of intimate partner violence: Is cessation of violence enough? Violence and Victimization, 18, 115-129.

MacPhillamy, D. J., \& Lewinsohn, P. M. (1982). The Pleasant Events Schedule: Studies on reliability, validity and scale intercorrelation. Journal of Consulting and Clinical Psychology, 50, 363-380.

Martin, S., Clark, K., Lynch, S., Kupper, L., \& Cilenti, D. (1999). Violence in the lives of pregnant teenage women: Associations with multiple substance use. American Journal of Drug and Alcohol Abuse, 25, 425-440.

McFarlane, J., Parker, B., Soeken, K., \& Bullock, L. (1992). Assessing for abuse during pregnancy. Journal of the American Medical Association, 267, 3176-3178.

O'Campo, P., McDonnell, K., Gielen, A., Burke, J., \& Chen, Y. (2002). Surviving physical and sexual abuse: What helps low-income women? Patient Education and Counseling, 46, 205-212.

O'Keefe, M., \& Treister, L. (1998). Victims of dating violence among high school students: Are the predictors different for males and females? Violence Against Women, 4, 195-223.

Osofsky, J. D., Hann, D. M., \& Peebles, C. (1993). Adolescent parenthood: Risks and opportunities for parents and infants. In C. Zeanah (Ed.), Handbook of infant mental health (pp. 106-119). New York: Guilford Press.

Parker, B., McFarlane, J., \& Soeken, K. (1994). Abuse during pregnancy: Effects on maternal complications in adult and teenage women. Journal of Obstetrics and Gynecology, 84, 323-328.

Parker, B., McFarlane, J., Soeken, K., Torres, S., \& Campbell, D. (1993). Physical and emotional abuse in pregnancy: A comparison of adult and teenage women. Nursing Research, 42, 173-178.

Radloff, L. S. (1977). The CES-D scale: A self-report depression scale for research in the general population. Applied Psychological Measurements, 1, 385-401.

Richardson, R., Barbour, N., \& Bubenzer, D. (1995). Peer relationships as a source of support for adolescent mothers. Journal of Adolescent Research, 10, 278-290.

Roberts, T., Klein, J., \& Fisher, S. (2003). Intimate partner abuse and high-risk behavior in adolescents. Archives of Pediatric and Adolescent Medicine, 157, 875-881.

Silverman, J., Raj, A., Mucci, L., \& Hathaway, J. (2001). Dating violence against adolescent girls and associated substance use, unhealthy weight control, sexual risk behavior, pregnancy, and suicidality. Journal of the American Medical Association, 286, 572-579. 
Valois, R., Oeltmann, J., Waller, J., \& Hussey, J. (1999). Relationship between number of sexual intercourse partners and selected health risk behaviors among public high school adolescents. Journal of Adolescent Health, 25, 328-335.

Walton, M., Weatherall, A., \& Jackson, S., (2002). Romance and sexuality in pre-teen stories about conflicts. Discourse and Society, 13, 681-697.
Wiemann, C., Agurcia, C., Berenson, A., Volk, R., \& Rickert, V. (2000). Pregnant adolescents: Experiences and behaviors associated with physical assault by an intimate partner. Maternal and Child Health Journal, 4, 93-101. Zimet, G., Dahlem, N., Zimet, S., \& Farley, G. (1988). The Multidimensional Scale of Perceived Social Support. Journal of Personality Assessment, 52, 30-41. 